\title{
QBD APPROACH TO ANALYTICAL METHOD DEVELOPMENT AND ITS VALIDATION FOR ESTIMATION OF LENVATINIB IN BULK AND PHARMACEUTICAL FORMULATION
}

\author{
SACHIN A. BABAR ${ }^{1}$, SUDHAKAR L. PADWAL ${ }^{2}$
}

1,2Department of Chemistry, K. B. P. Mahavidyalaya Pandharpur, Punyashlok Ahilyadevi Holkar Solapur University, Solapur India 413255 Email: sachin.babar86@gmail.com

Received: 13 Apr 2021, Revised and Accepted: 05 Aug 2021

\section{ABSTRACT}

Objective: The objective of this research was to develop a simple, very rapid, sensitive, accurate, precise reverse phase High-Performance Liquid Chromatography (RP-HPLC) technique for the estimation of Lenvatinib in bulk and its dosage form.

Methods: To perform this study, we employed a central composite design (CCD) to make method robust and effective to create chromatographic database. The factor screening studies were performed using 2-factor 10-runs. The factors were selected as the mobile phase ratio and buffer pH.

Results: The desirability value of the optimized model was found to be 0.869 and The optimized chromatographic condition was achieved on Enable C18 analytical column with 0.01M Ammonium acetate buffer pH 3.84: methanol (33.17:66.83 v/v) as the mobile phase and flow rate of 1 ml min-1 and detection wavelength was set to $240 \mathrm{~nm}$. The retention time of Lenvatinib was found to be 5.122 min. Linearity was established for Lenvatinib in the range of $10-50 \mu \mathrm{g} / \mathrm{ml}$ with a correlation coefficient ( $\mathrm{r} 2=0.9995$ ). The accuracy values were found to be in the range of $98-102 \%$. Intraday precision and Interday precision were in prescribed (Less than $0.98 \%$ RSD). Robustness was found to be less than $1.22 \%$ RSD.

Conclusion: The proposed method was useful for best analysis of Lenvatinib in Bulk pharmaceutical dosage forms. Central Composite Design was an effective tool for the proposed RP-HPLC method.

Keywords: Quality by design, Design expert 8, RP-HPLC, Lenvatinib

(C) 2021 The Authors. Published by Innovare Academic Sciences Pvt Ltd. This is an open access article under the CC BY license (https://creativecommons.org/licenses/by/4.0/) DOI: https://dx.doi.org/10.22159/ijap.2021v13i5.41786. Journal homepage: https://innovareacademics.in/journals/index.php/ijap

\section{INTRODUCTION}

Lenvatinib is chemically 4-\{3-chloro-4-[(cyclopropyl carbamoyl) amino] phenoxy\}-7-methoxyquinoline-6-carboxamide and having molecular formula $\mathrm{C}_{21} \mathrm{H}_{19} \mathrm{ClN}_{4} \mathrm{O}_{4}$. Lenvatinib is a receptor tyrosine kinase (RTK) inhibitor that inhibits the kinase activities of vascular endothelial growth factor (VEGF) receptors VEGFR1 (FLT1), VEGFR2 (KDR), and VEGFR3 (FLT4). Lenvatinib also inhibits other RTKs that have been implicated in pathogenic angiogenesis, tumor growth, and cancer progression in addition to their normal cellular functions, including fibroblast growth factor (FGF) receptors FGFR1, 2, 3, and 4; the platelet derived growth factor receptor alpha (PDGFR $\alpha$ ), KIT, and RET. These receptor tyrosine kinases (RTKs) located in the cell membrane play a central role in the activation of signal transduction pathways involved in the normal regulation of cellular processes, such as cell proliferation, migration, apoptosis and differentiation, and in pathogenic angiogenesis, lymphogenesis, tumour growth and cancer progression [1-3].

According to the previous study, we got bioanalytical method development, RP-HPLC method development and their validation, stability indicating method development etc but nobody went for statistical approach like Quality by design due that we selected Lenvatinib.

Quality by Design is a novel approach to estimate Lenvatinib in bulk as well as a pharmaceutical formulation. Central composite design gave runs for optimization. In this study, we selected no of mobile phases, $\mathrm{pH}$ of aqueous phase and flow rate. No one went for such a chromatographic variation and their observation.

Objectives of the present research were to develop routine analytical method development and its validation by using quality by design approach. We have used central composite design and quadratic model. We have succeeded in optimizing overall model with desirability 0.869 .

\section{MATERIALS AND METHODS}

\section{Material}

Chemicals

Lenvatinib and its formulation (Lenvima $10 \mathrm{mg}$, Sun Pharma Ltd), acetonitrile, methanol, ammonium format buffer, triethylamine, orthophosporic acid and distilled water.

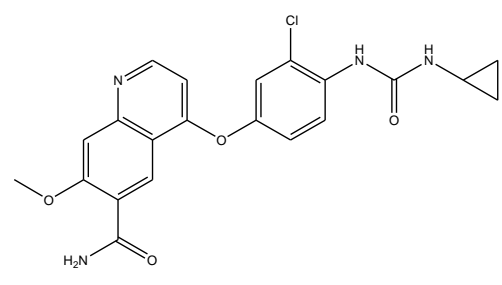

Fig. 1: Structure of lenvatinib

\section{Methods}

Preliminary analysis of drug

Color and texture of Lenvatinib were compared with reported characters mentioned in the drug bank.

Solubility of Lenvatinib was determined sparingly soluble in acetic acid and slightly soluble in water, N, N-dimethylformamide, methanol, N-methylpyrrolidone, and pyridine. UV analysis was carried out by scanning the solution of Lenvatinib at $200-400 \mathrm{~nm}$ [1-3].

\section{Design of experiment}

\section{Central composite designs}

The most popular response surface method (RSM) design is the central composite design (CCD). A CCD has three groups of design points:
(a) Two-level factorial or fractional factorial design points
(b) Axial points (sometimes called "star" points)
(c) Centre points

CCD's are designed to estimate the coefficients of a quadratic model. All point descriptions will be in terms of coded values of the factors. Present study we have used center point and factorial design with following factors like mobile Phase, $\mathrm{pH}$ of buffer, flow Rate and 
Independent factors are retention Time, peak area, theoretical Plate and peak asymmetry. The $\mathrm{C}^{18}$ column has been selected for routine analytical method.

Factorial design has flexibility to change/add/delete any parameter at any time when our experiment is going on. it provides facility to give standard run at one time at only one mobile phase. Three independent factors have been selected. Mobile phases are selected as Buffer: Methanol, Water: Methanol and Water: Acetonitrile [4-9].

Dependent factors were selected as mobile Phase, $\mathrm{pH}$ of buffer and independent factors were retention time, peak area, theoretical plate and peak asymmetry. $\mathrm{C}^{18}$ Column used for the separation of Lenvatinib. Mobile phases selected as phosphate buffer: acetonitrile, ammonium acetate buffer: methanol and water: methanol. Central Composite Factorial design facilitates only one mobile phase like ammonium acetate buffer: Methanol, change $\mathrm{pH}$ range: $4-6 \mathrm{mmol} / \mathrm{l}$ and change mobile phase proportion range: $60-70 \%$ (consider organic phase).

When all above ranges put in Central Composite design, it gave 10 run at different $\mathrm{pH}$ and Mobile phase proportion with flow rate is maintained constant at $1 \mathrm{ml} / \mathrm{min}$ followed by same procedure for each mobile phase. Total runs of design are 30 . After completion of all trials, screening and optimization is done for best desirability value that is 1.00. Optimization means finding an alternative with the most cost effective or highest achievable performance under the given constraints, by maximizing desired factors and minimizing undesired ones. In comparison, maximization means trying to attain the highest or maximum result or outcome without regard to cost or expense. Trails suggested by software are as given in table no 4 [4-9].

Table 1: Factors and responses considered for study suggested by the software

\begin{tabular}{lll}
\hline S. No. & $\begin{array}{l}\text { Mobile phase composition } \\
\text { (Organic phase) }\end{array}$ & pH of Buffer \\
\hline 1 & 70.00 & 3.00 \\
2 & 65.00 & 4.00 \\
3 & 70.00 & 5.00 \\
4 & 65.00 & 2.00 \\
5 & 72.00 & 4.00 \\
6 & 65.00 & 5.00 \\
7 & 65.00 & 4.00 \\
8 & 52.00 & 4.00 \\
9 & 60.00 & 5.00 \\
10 & 60.00 & 3.00 \\
\hline
\end{tabular}

\section{Preparation of mobile phase}

$65 \mathrm{ml}$ of HPLC grade Methanol and $35 \mathrm{ml}$ of $0.01 \mathrm{M}$ Ammonium acetate Buffer $\mathrm{pH}$ was adjusted to 4.0 with orthophosphoric acid i.e. in 65: $35 \mathrm{v} / \mathrm{v}$ proportions. The solution was filtered through $0.45 \mu$ membrane filter and then sonicated for $10 \mathrm{~min}$ [4-9].

\section{Preparation of stock solutions of lenvatinib}

Stock solution was prepared by dissolving $10 \mathrm{mg}$ Lenvatinib in methanol and then diluted with methanol in $10 \mathrm{ml}$ of volumetric flask to get concentration of $1000 \mu \mathrm{g} / \mathrm{ml}$. From the resulting solution $0.4 \mathrm{ml}$ was diluted to $10 \mathrm{ml}$ with methanol to obtain concentration of 40 $\mu \mathrm{g} / \mathrm{ml}$ of Lenvatinib and labeled as standard stock Lenvatinib [4-9].

\section{Selection of detection wavelength}

From the standard stock solution further dilutions were done using water and scanned over the range of 200-400 $\mathrm{nm}$ and the spectra were overlain. It was observed that drug showed considerable absorbance at $240 \mathrm{~nm}$.

\section{RESULTS AND DISCUSSION}

\section{Optimization}

\section{Screening design for suitable chromatographic condition}

- Ammonium acetate buffer: Acetonitrile; Some peaks observed with high peak asymmetric factor, more retention time and less theoretical Plates: Overall observations were partially satisfactory.

- Ammonium acetate buffer: Methanol: Peaks observed with less peak asymmetry, less retention time and more theoretical plates: Overall observations were Extremely Satisfactory.

- Water: Methanol: Some proportions did not show peaks and some proportion did not have good peak properties: Overall observations were Dissatisfactory.

Suitable chromatographic conditions are given by software on the basis of desirability result. After screening of models, result of desirability was found to be 0.869 [4-9].

\section{Optimized chromatographic conditions}

Mobile phase: $0.01 \mathrm{M}$ Ammonium acetate buffer: Methanol (33.17:66.83 v/v), pH of Buffer 3.84 and Flow rate $1.00 \mathrm{ml} / \mathrm{min}$. Analytical column: $\mathrm{C}_{18}$ column Waters XBridge $(4.6 \times 150 \mathrm{~mm} \times 5$ $\mu \mathrm{m})$, UV detection: $240 \mathrm{~nm}$, Injection volume: $10 \mu \mathrm{l}$, Flow rate: $1.0 \mathrm{ml}$ min-1, Temperature: Ambient, Run time: 10 min.

Table 2: Optimized chromatographic conditions

\begin{tabular}{|c|c|c|c|c|c|c|c|}
\hline S. No. & Amount of methanol & pH of buffer & Flow rate & Retention time & Tailing factor & Theoretical plates & Desirability \\
\hline 1 & 66.83 & 3.84 & 1 & 5.122 & 1.0698 & 11237.8 & 0.869 \\
\hline
\end{tabular}

\section{Effect of independent variables on retention time (X)}

After applying experimental design, the suggested Response Surface Linear Model was found to be significant with model F value of 80.20, p value less than 0.005 and $R^{2}$ value of 0.9901 . There is only a $0.04 \%$ chance that a "Model F-Value" this large could occur due to noise. Values of $\%$ C. V. and adjusted $\mathrm{R}^{2}$ were 5.82 and 0.9778 , respectively [4-9].

\section{The equation for response surface quadratic model is as follows}

Retention time $=+93.15940-2.30696 *$ Mobile Phase $+0.71192 * \mathrm{pH}$ of Buffer- $0.017850 *$ Mobile Phase $*$ pH of Buffer $+0.014857 *$ Mobile Phase2+0.058938* pH of Buffer2 Fig. 2 shows a graphical representation of $\mathrm{pH}$ of buffer (B) and amount of Methanol (A), as increases in $\mathrm{pH}$ does not showed change in retention time $(\mathrm{X})$, but increase in amount of Methanol showed decreases the retention time.

Fit summary: Surface Linear Model was suggested by the software.

ANOVA: ANOVA of developed central composite model for retention time $(\mathrm{X})$

Values of "Prob $>F$ " (p-value) less than 0.0500 indicate model terms are significant. In this case A and C are significant model terms (table 3).

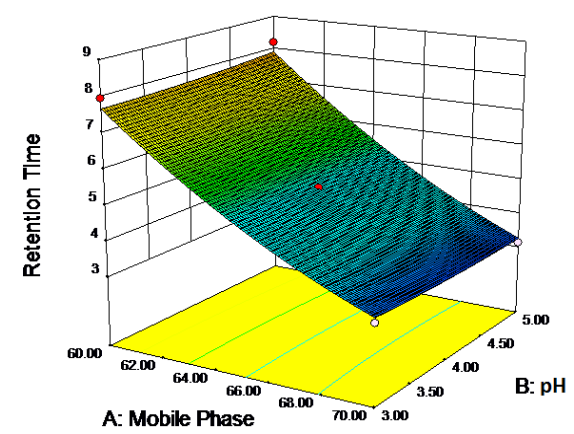

Fig. 2: Three-dimensional plot for retention time as a function of $\mathrm{pH}$ of buffer and amount of methanol. Constant factor (flow rate-1 $\mathrm{ml} \mathrm{min}^{-1}$ )

\section{Effect of independent variables on asymmetric factor (Y)}

After applying experimental design, the suggested Response Surface Linear Model was found to be significant with model F value of 7.59, 
$p$ value less than 0.005 and $R^{2} v a l u e$ of 0.9047 . There is only a $3.60 \%$ chance that a "Model F-Value" this large could occur due to noise.
Values of \% C. V. and adjusted $\mathrm{R}^{2}$ were 10.01 and 0.7855 respectively [4-9].

Table 3: Significance of $p$ value on model terms of retention time

\begin{tabular}{llll}
\hline Model terms & p value & Effect of factor & Remarks \\
\hline A & 0.0001 & 39.94 & Significant \\
B & 0.8470 & $4.295 E-003$ & Insignificant \\
Overall model & 0.0004 & - & Significant \\
\hline
\end{tabular}

The equation for response surface quadratic model is as follows

Asymetric factor $=+52.09377-1.46656 *$ Mobile Phase-2.27090*pH of Buffer-2.00000E-003 *Mobile Phase *pH of Buffer+0.011552* Mobile Phase $2+0.31356 * \mathrm{pH}$ of Buffer 2

Fig. 3 shows a graphical representation of $\mathrm{pH}$ of buffer (B) and amount of Methanol (A), at the point of $\mathrm{pH} 4$ showed positive effects on asymmetric factor (Y), but decreases in the amount of Methanol showed slightly decreases the asymmetric factor.

Fit summary: Response Surface Quadratic Model was suggested by the software.

ANOVA: ANOVA of developed centre composite model for asymmetric factor $(\mathrm{Y})$.

Values of "Prob>F" (p-value) less than 0.0500 indicate model terms are significant. In this case, $\mathrm{A}$ and $\mathrm{C}$ are significant model terms (table 4).

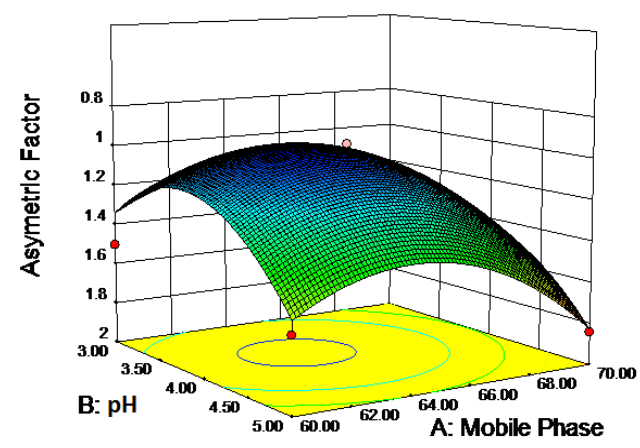

Fig. 3: Three-dimensional plot for asymmetric factor as a function of $\mathrm{pH}$ of buffer and amount of Methanol. Constant factor (flow rate-1 $\mathrm{ml} \mathrm{min}^{-1}$ )

Table 4: Significance of $p$ value on model terms of retention time

\begin{tabular}{llll}
\hline Model terms & p value & Effect of factor & Remarks \\
\hline A & 0.0591 & 0.15 & Significant \\
B & 0.1078 & 0.093 & Insignificant \\
Overall model & 0.0360 & - & Significant \\
\hline
\end{tabular}

\section{Effect of independent variables on theoretical plates (Z)}

After applying experimental design, suggested Response Surface Linear Model was found to be significant with model $F$ value of 18.10 , $p$ value less than 0.005 and $\mathrm{R}^{2}$ value of 0.9577 . There is only a $0.75 \%$ chance that a "Model F-Value" this large could occur due to noise. Values of $\% \mathrm{C}$. V. and adjusted $\mathrm{R}^{2}$ were 8.16 and 0.9048 respectively [4-9].

\section{The equation for response surface quadratic model is as follows}

Theoretical Plates $=-3.09773 \mathrm{E}+005+9274.53098 *$ Mobile Phase $+4091.85610 * \mathrm{pH}$ of Buffer $+136.60000 *$ Mobile Phase * ${ }^{*} \mathrm{H}$ of Buffer-73.19750*Mobile Phase2-1536.68750* ${ }^{*} \mathrm{pH}$ of Buffer 2 fig. 4 shows a graphical representation of $\mathrm{pH}$ of buffer (B) and amount of Methanol (A), as increases in $\mathrm{pH}$ does not showed change in retention time $(\mathrm{X})$, but increase in amount of Methanol showed decreases the retention time.

Fit summary: Response Surface Quadratic Model was suggested by the software.

ANOVA: ANOVA of developed central composite model for theoretical plates (Z)

Values of "Prob>F" (p-value) less than 0.0500 indicate model terms are significant. In this case, A and C are significant model terms (table 5)

\section{Method validation}

The proposed HPLC method was validated in terms of system suitability, specificity, precision, accuracy and robustness as per the International Conference on Harmonization (ICH) guidelines (7).

\section{Linearity and range}

The linearity response was determined by analysing 5 independent levels of calibration curve in the range of $10-50 \mu \mathrm{g} / \mathrm{ml}$ for Lenvatinib. The stock solutions of standard Lenvatinib were diluted to six different known concentrations. Linearity graph of concentration (as $\mathrm{x}$-value) versus area (as $\mathrm{y}$-value) were plotted and correlation coefficient, $y$-intercept and slope of the regression were calculated. [4-13] Result and fig. is given in table 6 and fig. 5.

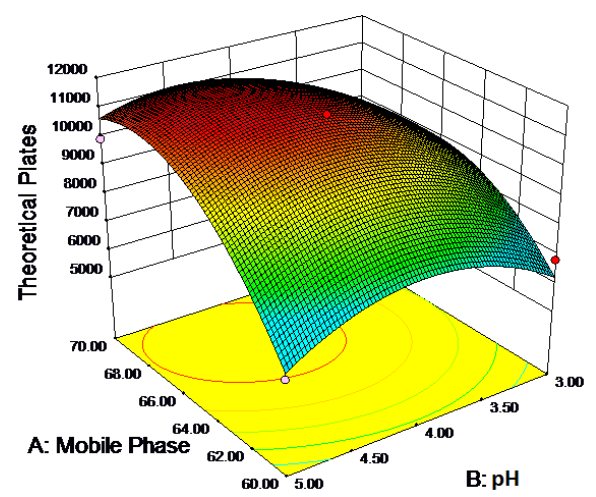

Fig. 4: Three-dimensional plot for theoretical plates as a function of $\mathrm{pH}$ of buffer and amount of methanol. Constant factor (flow rate-1 $\mathrm{ml} \mathrm{min}^{-1}$ )

Table 5: Significance of $p$-value on model terms of retention time

\begin{tabular}{llll}
\hline Model terms & p-value & Effect of factor & Remarks \\
\hline A & 0.0033 & $1.864 \mathrm{E}+007$ & Significant \\
B & 0.0493 & $3.670 \mathrm{E}+006$ & Significant \\
Overall model & 0.0075 & & Significant \\
\hline
\end{tabular}


Table 6: Linearity result of lenvatinib

\begin{tabular}{lll}
\hline S. No. & Concentration $(\boldsymbol{\mu g} / \mathbf{m l})$ & Peak area \\
\hline 1 & 10 & 112747 \\
2 & 20 & 225495 \\
3 & 30 & 339243 \\
4 & 40 & 460990 \\
5 & 50 & 563738 \\
\hline
\end{tabular}

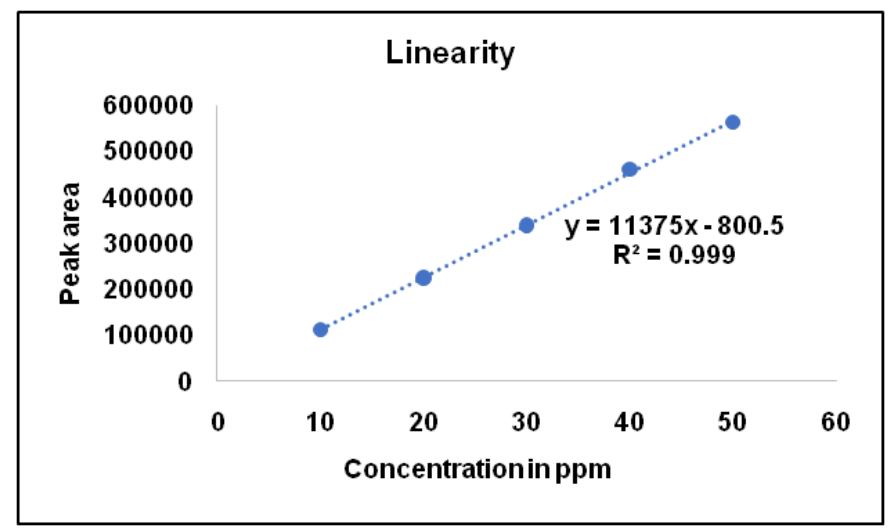

Fig. 5: Calibration curve of lenvatinib

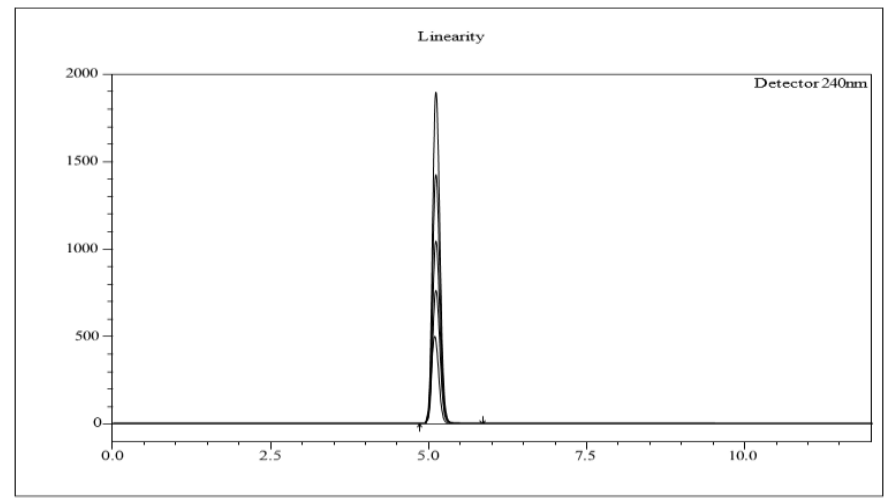

Fig. 6: Overlain of lenvatinib

Table 7: Characteristic parameters of lenvatinib for the proposed HPLC method

\begin{tabular}{lll}
\hline S. No. & Parameter & Result \\
\hline 1 & Calibration range $(\mu \mathrm{g} / \mathrm{ml})$ & $10-50$ \\
2 & Detection wavelength $(\mathrm{nm})$ & 240 \\
3 & Solvent (Buffer: Methanol) & $33.17: 66.83 \mathrm{v} / \mathrm{v}$ \\
4 & Regression equation $\left(\mathrm{y}^{*}\right)$ & $\mathrm{y}=11375 \mathrm{x}-800.5$ \\
5 & Slope $(\mathrm{b})$ & 11375 \\
6 & Intercept $(\mathrm{a})$ & 800.5 \\
7 & Correlation coefficient $(\mathrm{r} 2)$ & 0.9995 \\
8 & Limit of Detection $(\mu \mathrm{g} / \mathrm{ml})$ & 1.435 \\
9 & Limit of Quantitation $(\mu \mathrm{g} / \mathrm{ml})$ & 4.35 \\
\hline
\end{tabular}

\section{System suitability}

System-suitability tests are an integral part of method development and are used to ensure the adequate performance of the chromatographic system (fig. 6) Retention time, the number of theoretical plates $(\mathrm{N})$ and tailing factor $(\mathrm{T})$ were evaluated for six replicate injections of the drug at a concentration of $40 \mu \mathrm{g} / \mathrm{ml}$. The results which are given in table 7 and table 8 were within acceptable limits [4-13].

Table 8: System suitability studies of lenvatinib by HPLC method

\begin{tabular}{lll}
\hline S. No. & Properties & Values \\
\hline 1. & Retention time & 5.122 \\
2. & Area & 461025 \\
3. & Asymmetry & 1.18 \\
4. & Theoretical plates & 12458 \\
\hline
\end{tabular}




\section{Specificity}

The effect of excipients and other additives usually present in the dosage form of Lenvatinib in the determination under optimum conditions was investigated. Lenvatinib showed a peak at a retention time of 5.112 min. The mobile phase designed for the method resolved the drug very efficiently. The Retention time of Lenvatinib was $5.113 \pm 0.0098 \mathrm{~min}$. The wavelength $240 \mathrm{~nm}$ was selected for detection because; it resulted in better detection sensitivity for the drug. The peak for Lenvatinib from the tablet formulation was Lenvatinib [4-13].

\section{Precision}

Demonstration of precision was done under two categories. The injection repeatability (System Precision) was assessed by using six injections of the standard solution of Lenvatinib and the \% RSD of the replicate injections was calculated. In addition, to demonstrate the precision of method (Method Precision), six samples from the same batch of formulation were analysed individually and the assay content of each sample was estimated. The average for the six determinations was calculated along with the \% RSD for the replicate determinations. Both the system precision and method precision were subjected for inter-day and intra-day variations as reported in table 09 and 10, respectively [4-13].

\section{Accuracy}

Recovery studies by the standard addition method were performed with a view to justifying the accuracy of the proposed method. Previously analysed samples of Lenvatinib $(40 \mu \mathrm{g} / \mathrm{ml})$ were spiked with 80,100, and $120 \%$ extra Lenvatinib standard and the mixtures were analysed by the proposed method [4-13]. Standard deviation of the $\%$ recovery and \% RSD was calculated and reported in table 11 .

Table 9: Intraday precision of lenvatinib at $240 \mathrm{~nm}$

\begin{tabular}{llll}
\hline Concentration & Peak area & & \\
\cline { 2 - 4 } & $\mathbf{0 ~ H}$ & $\mathbf{2 ~ H}$ & $\mathbf{3} \mathbf{H}$ \\
\hline 40 & 471021 & 469020 & 461020 \\
40 & 468998 & 465091 & 456990 \\
40 & 465125 & 460974 & 465423 \\
40 & 460901 & 470092 & 466487 \\
40 & 470988 & 459990 & 459810 \\
40 & 462990 & 464292 & 468864 \\
Mean & 466671 & 4469.69 & 463099 \\
SD & 4294.34 & 0.96 & 4529.34 \\
\hline
\end{tabular}

Values are expressed as mean $\pm \mathrm{SD}, \mathrm{n}=3$

Table 10: Interday precision of lenvatinib at $240 \mathrm{~nm}$

\begin{tabular}{llll}
\hline Concentration & Peak area & & \\
\cline { 2 - 4 } & $\mathbf{1 ~ d}$ & $\mathbf{2 ~ d}$ & \\
\hline 40 & 471021 & 469593 & 468786 \\
40 & 468998 & 467132 & 476954 \\
40 & 465125 & 469018 & 475420 \\
40 & 460901 & 469018 & 479358 \\
40 & 470988 & 458293 & 468232 \\
40 & 462990 & 469597 & 469846 \\
Mean & 466671 & 467109 & 473099 \\
SD & 4294.34 & 4412.97 & 4739.09 \\
RSD & 0.92 & 0.94 & 1.00 \\
\hline
\end{tabular}

Values are expressed as mean $\pm \mathrm{SD}, \mathrm{n}=3$

Table 11: Accuracy of lenvatinib at $240 \mathrm{~nm}$

\begin{tabular}{|c|c|c|c|}
\hline S. No. & Concentration & Found concentration & Recovery \% \\
\hline 1 & 40 & 39.94 & 100.08 \\
\hline 4 & 50 & 49.96 & 99.97 \\
\hline 8 & 60 & 59.97 & 100.33 \\
\hline
\end{tabular}

Table 12: Robustness of lenvatinib at the wavelength

\begin{tabular}{lll}
\hline Conc. $(\boldsymbol{\mu g} / \mathbf{m l})$ & Wavelength & $\mathbf{2 3 8} \mathbf{~ n m}$ \\
\cline { 2 - 3 } & $\mathbf{2 4 0} \mathbf{~ n m}$ & 329156 \\
40 & 471021 & 325794 \\
40 & 468998 & 319848 \\
40 & 465125 & 321688 \\
40 & 460901 & 328779 \\
40 & 470988 & 321899 \\
40 & 462990 & 324527.3 \\
Sean & 466670.5 & 3948.97 \\
RSD & 4294.34 & 1.22 \\
\hline
\end{tabular}

Values are expressed as mean $\pm \mathrm{SD}, \mathrm{n}=3$ 


\section{Robustness}

Robustness is a measure of the capacity of a method to remain unaffected by small but deliberate variations in the method conditions and is indications of the reliability of the method. A method is robust, if it is unaffected by small changes in operating conditions. To determine the robustness of this method, the experimental conditions were deliberately altered at three different levels and retention time and chromatographic response was evaluated. One factor at a time was changed to study the effect. Variation of Wavelength and Temperature had no significant effect on the retention time and chromatographic response of the 40 $\mu \mathrm{g} / \mathrm{ml}$ solution, indicating that the method was robust. The results are shown in table 12 [4-13].

\section{CONCLUSION}

Our current experiment illustrates the development and validation of a simple, rapid, and very sensitive RP-HPLC method developed for the determination of Lenvatinib in pure form and dosage forms. This developed experiment overcomes the drawbacks that have been found in the other reported method where no need to use the isocratic method, more retention time, and complex extraction for this simple method. Also, this method is money-saving as it needs less expensive instrumentations, solvents, and reagents. The high accuracy, precision, and sensitivity make this simple method be a reliable and reproducible method to be applied in quality control.

\section{FUNDING}

Nil

\section{AUTHORS CONTRIBUTIONS}

All authors have contributed equally.

\section{CONFLICT OF INTERESTS}

Declared none

\section{REFERENCES}

1. Patve RS, Shaikh AR, Inamdar N, Bhise K. Method development and validation of lenvatinib by HPLC and UV-spectroscopy. Indian Drugs 2018;55:39-7.

2. Prashanthi Y, Ahmed MA, Vijaya K, Riyazuddin. Method development and validation of lenvatinib drug by RP-HPLC in pharmaceutical drug dosage form, Indo. Am J Pharm Sci 2016;3:1078-85.
3. Panigrahy UP, Reddy AK. A novel validated RP-HPLC-DAD method for the estimation of lenvatinib mesylate in bulk and pharmaceutical dosage form. J Chem Pharm Res 2015;7:872-81.

4. Waghmare SA, Sumithra M. Full factorial experimental design for development and validation of RP-HPLC method for estimation of apixaban in bulk and pharmaceutical formulations. J Seybold Rep 2020;15:3428-42.

5. Waghmare SA, Kale PB, Desai RS, Takale S, Jadhav M, Bayas JP. Analytical method development and validation for determination of telmisartan in bulk and pharmaceutical formulation by QbD approach. IJAEMA 2020;12:1567-71.

6. Pukale AK, Giri SS, Waghmare SA. Qbd approach to UV-visible spectroscopic method development and validation for the estimation of ranolazine in bulk and pharmaceutical formulation. Eur J Biomed Pharm Sci 2018;5:740-5.

7. Waghmare SA, Kashid AM. Reverse phase-high performance liqui chromatography method development and validation for estimation of efavirenz by quality by design approach. J Drug Delivery Ther 2019;9:319-30.

8. Sanap A, Choudhary PS, Kale PB, Waghmare SA. Analytical method development and validation for estimation of oseltamivir phosphate in bulk and pharmaceutical formulation by QbD approach. IJAEMA 2020;12:463-70.

9. Giri SS, Pukale AK, Waghmare SA. Spectroscopic method development and validation for estimation of apixaban in bulk and pharmaceutical formulation by QbD approach. Eur J Biomed Pharm Sci 2018;5:637-42.

10. Rajkotwala S, Shaikh SS, Dedania ZR, Dedania RR, Vijendraswamy SM. QbD Approach to analytical method development and validation of piracetam by HPLC. World J Pharm Pharm Sci 2016;5:1771-84.

11. Garg NK, Sharma G, Singh B, Nirbhavane P, Katare OP. Quality by design (QbD)-based development and optimization of a simple, robust RP-HPLC method for the estimation of methotrexate. J Liq Chromatogr Relat Technol 2015;38:1629-37.

12. Mandlik SK, Agrawal PP, Dandgavhal HP. Implementation of quality by design (Qbd) approach in formulation and development of ritonavir pellets using extrusion spheronization method. Int J Appl Pharm 2020;12:139-46.

13. Srujani $\mathrm{CH}$, Annpurna $\mathrm{P}$, Nataraj KS, Pawar KM. Analytical quality by design approach in RP-HPLC method development and validation for the estimation of duvelisib. Asian J Pharm Clin Res 2021;14:99-108. 